\title{
The case of encephalitis in a COVID-19 pediatric patient
}

\author{
Lidia Urso ${ }^{1} \cdot$ Maria Grazia Distefano ${ }^{1} \cdot$ Gaetano Cambula $^{2}$ - Angela Irene Colomba ${ }^{1}$ Domenico Nuzzo $0^{3,4} \oplus$. \\ Pasquale Picone $^{3,4}$. Daniela Giacomazza ${ }^{5}$. Luigi Sicurella ${ }^{1}$
}

Received: 23 June 2021 / Accepted: 15 October 2021 / Published online: 19 October 2021

(C) Fondazione Società Italiana di Neurologia 2021

\begin{abstract}
Background The COVID-19 pandemic, induced by the worldwide spreading of the SARS-CoV-2, is well known for its clinical picture consistent with respiratory symptoms. If pulmonary complications are the most common manifestation of the disease, neurological problems are also significantly present, with complications including acute cerebrovascular events, encephalitis, Guillain-Barré and Miller Fisher syndromes, acute necrotizing hemorrhagic encephalopathy and hemophagocytic lymphohistiocytosis. These medical signs can be considered direct effects of the virus on the nervous system, parainfectious or post-infectious immune-mediated diseases, and neurological complications of the systemic effects of the SARS-CoV-2.

Case In the present article, the encephalitis case in a 5-year-old girl positive for COVID-19 admitted to the emergency department complaining of fever and swelling in the neck is described. At this time, her neurological examination was unremarkable. Over the next few days, the fever went down and she experienced acute behavioral changes, mild confusion, and drowsiness. The brain MRI and electroencephalography (EEG) showed CNS involvement, suggestive of encephalitis.

Conclusion The dramatic improvement of the symptoms after immunotherapy with corticosteroids reinforced the hypothesis of an immune-related mechanism.
\end{abstract}

Keywords COVID-19 $\cdot$ SARS-CoV-2 $\cdot$ Neurological manifestations $\cdot$ Pediatric patient $\cdot$ Encephalitis

\section{Introduction}

Occasional viral encephalitis in children and young adults include a large and heterogeneous group of inflammatory brain diseases, characterized by different symptoms and variable onset. The most frequent etiological agents are herpes simplex, varicella zoster, Epstein-Barr viruses, cytomegalovirus, human immunodeficiency virus (HIV), and enteroviruses [1]. The ways of access and propagation of the viruses are mainly the respiratory tract, the oral cavity, and also the peripheral nerves, and among them, the olfactory bulb represents a preferential route [2]. The differential

Luigi Sicurella

luigi.sicurella@asptrapani.it

1 Dipartimento di Neurologia P.O. S. Antonio Abate, Azienda Sanitaria Provinciale di Trapani, Trapani, Italy

2 Unità Operativa Complessa Radiologia P.O.S. Antonio Abate, Azienda Sanitaria Provinciale di Trapani, Trapani, Italy

3 Consiglio Nazionale delle Ricerche, Istituto per la Ricerca e l'Innovazione Biomedica (CNR-IRIB), Palermo, Italy

4 Dipartimento of Scienze Biologiche, Chimiche, Farmaceutiche e Tecnologiche (STEBICEF), University of Palermo, Palermo, Italy

5 Consiglio Nazionale delle Ricerche, Istituto di Biofisica (CNR-IBF), Palermo, Italy 
diagnosis between the various viral forms is complex, based on laboratory data, confirmed infection, and examination of the liquor. The neuroimaging also can highlight the presence of lesions in the brain parenchyma, confined in typical locations, prevalent prerogative of a specific viral agent [3].

MRI of the brain is the main examination, essential for the study of a patient suspected of suffering from encephalitis. The test allows performing morphological and functional study of the brain, with early identification of any lesion of the cerebral parenchyma, even in the hyperacute phase [3]. After injection of the paramagnetic contrast agent, the image sequence can resolve any alteration of the blood-brain barrier and associated meningeal modification [4].

SARS-CoV-2 is a large single-stranded RNA virus. The $S$ protein, protruding from the viral envelop, is the main antigenic component, constituted by the $\mathrm{S} 1$ and $\mathrm{S} 2$ subunits [5]. The cell invasion by SARS-CoV-2 begins with the binding of the virus to the angiotensin-converting enzyme 2 (ACE2) receptors, highly expressed in neurons and glial cells of the CNS and epithelial cells of respiratory system [6] and, to a lesser extent, in the kidneys, heart, adipose tissue, and reproductive organs of both sexes [7]. In the following step, the host transmembrane serine protease 2 cleaves the $\mathrm{S}$ protein at the junction between the two domains, causing the insertion of the S2 domain into the cell membrane and allowing the penetration of the viral genome into the host cell cytoplasm [7, 8]. The new viruses are assembled in the endoplasmic reticulum and Golgi apparatus and ready to infect any other cell expressing the ACE2 receptors.

The infection induced by the new SARS-CoV-2 occurs in various forms, from asymptomatic to severe, and usually they are strongly linked to the age and health conditions of the patients. In the symptomatic form, common manifestations include loss of smell and taste, fever, cough, sore throat, fatigue, and general feeling of malaise. Some gastrointestinal symptoms are also frequent, such as diarrhea, nausea, and anorexia [9-11].

Although the SARS-CoV-2 infection mainly affects the respiratory system causing, in the severe form, lung injuries and failure [12], the occurrence of neurological symptoms in COVID-19 patients is more and more evident and constantly growing. As experienced by numerous patients, also at the onset of the infection, clinical evidence has highlighted the marked neurotropism of the new SARS-CoV-2.

From a clinical point of view, the involvement of the CNS is manifested through the appearance of more or less serious symptoms, from headache, disturbances of smell, and anosmia, to impaired consciousness, acute cerebrovascular disease, ataxia, and seizure $[2,10,11]$. Pavone and coworkers [13] reported two cases of pediatric patients showing a temporal correlation between the insurgence of COVID-19 infection and the onset of pediatric acute neuropsychiatric syndrome, an obsessive-compulsive disorder associated with other cognitive, behavioral, and/or neurological symptoms [13].

The route for the invasion of the CNS typically starts in the peripheral tissues, and then the virus spreads to the peripheral nerves through which it reaches the CNS [10, 11]. Furthermore, the crossing of the blood-brain barrier directly from the bloodstream has been observed.

The virus can cause neurological disorders through the action of different mechanisms, that is, (i) hypoxic injury, (ii) hypercoagulability, and (iii) inflammatory response [14]. In the first one, patients with severe COVID-19 may develop serious shortness of breath and hypoxia [5]. During hypoxia, the excessive accumulation of anaerobic metabolites in the mitochondria and acid metabolites in the brain leads to edema of the brain cells and obstruction of the cerebral blood flow [15].

The hypercoagulability mechanism, frequently observed in patients with severe COVID-19 infection, could predispose to stroke [15]. A retrospective analysis revealed that abnormal coagulation, including markedly elevated levels of the D-dimer breakdown products and fibrin, longer prothrombin time, and activated partial thromboplastin time, is associated with a poor prognosis. Furthermore, disseminated intravascular coagulation is commonly associated with lethal COVID-19 form [16].

Several studies have indicated that the Sars-CoV-2 induces proinflammatory cytokine signals releasing a large amount of inflammatory factors such as IL-6, IL-12, IL-15, IL- $1 \beta$, and TNF- $\alpha[17,18]$. This is one of the pathophysiological processes responsible for neurological and brain damages caused by the inflammatory mechanism in SARS-Co-2 disease [18]. Cytokine storm can stimulate an immune attack in the body, causing multiple organ failure. These mechanisms can also act, simultaneously, in combination [19].

How SARS-CoV-2 can cause neurological effects in pediatric patients is still unclear [13]. The direct viral injury to neural cells through the olfactory nerves, the endothelial vascular damage due to the interaction with angiotensin-converting enzyme 2 receptors, and the inflammatory response are the hypothesized mechanisms [13].

Although the clinical picture of the acute phase of Covid19 is, in itself, very complex and affects many organs, recent studies have identified a new consequence of SARS-CoV-2 infection with medium- and long-term effects, involving the nervous system, called Post-COVID-19 Neurological Syndrome. Although it mainly occurs in patients with severe COVID-19 forms, it can even affect patients with mildCOVID-19 infection and it concerns one-third of the SARSCoV-2-affected people [11]. The pathology originates from molecular mechanisms that give rise to neuroinflammation, compromises the social skills and quality of life of the 
affected patients and it will represent the new challenge in the fight against coronavirus in the next future [11, 20-22].

\section{Case report}

In October 2020, a 5-year-old previously healthy girl started experiencing some mild, self-limiting cough symptoms associated with a fever episode. Family and patient histories did not indicate anything significant and no medication was taken by the girl. A couple of days later, she was admitted to the emergency department complaining of a painful swelling in her neck. She especially presented a painful tumefaction in the right latero-cervical area, with a large erythematous patch of the overlying skin. The patient showed negativity to SARS-CoV-2 infection, as indicated by rapid swab test.

Therefore, due to the clinical suspect of lymph node abscess, an ultrasound of the neck was immediately requested and performed (Fig. 1). The study highlighted the presence, in correspondence with the clinical finding, of multiple lymph nodes with oval morphology and a slightly inhomogeneous and hypoechoic structure (size of about 1.6 $\mathrm{cm}$ ), while normal morphology in the lymph nodes on the left side was observed.

On the next day, the little patient underwent a standard chest X-ray examination and ultrasound test of the complete abdomen. They were both normal.

In the following days, a sudden worsening of the clinical conditions was observed with the appearance of neurological symptoms such as altered mental status, increased irritability, sleepiness, lack of energy, and lethargy.

Serological investigations for HSV1, varicella-zoster, Epstein-Barr, and CMV were negative. The RT-PCR test for SARS-CoV-2 was performed using a nasopharyngeal swab which was positive. Arterial blood gas analysis indicated a $\mathrm{PO}_{2} / \mathrm{FiO}_{2}$ ratio of $240 \mathrm{mmHg}$. Electroencephalogram did not display any significant epileptic discharges, but a widespread

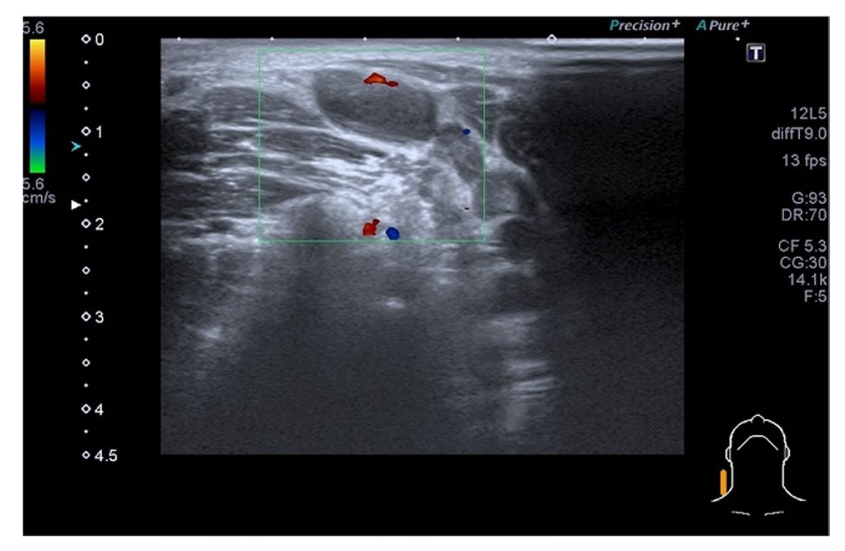

Fig. 1 Ultrasound of the neck indicating the lymph node swelling slowing of the underlying rhythm. The EEG (Fig. 2) showed a slow base rhythm (theta-delta) together with synchronous bilateral potentials formed by slow waves with predominance on the right side.

A MRI examination of the brain was immediately requested, with and without contrast medium.

The MRI studies were promptly performed at the Radiology Unit of the hospital on 1.5-T MR scanner. The sequences included fast spin echo (FSE), diffusion-weighted imaging (DWI), T1WI, T2-weighted imaging (T2WI), and T2-fluidattenuated inversion recovery (T2-FLAIR) in the axial plane, T2WI or T2-FLAIR in the sagittal plane, and CE T1WI in the axial, coronal, and sagittal planes after injection of 0.1 $\mathrm{mmol} / \mathrm{kg}$ of GBCAs (Fig. 3).

Axial DWI demonstrated the presence of a hyperintense focal lesion in the splenium of the corpus callosum, which appeared slightly swollen, and an additional area with the same signal characteristics in the right parietal subcortical area. In the long TR sequences, the lesions appeared hyperintense, but did not show any contrast enhancement.

The remaining regions were within limits.

These lesions were compatible with parenchymal cerebral edema due to brain inflammation in accordance with the diagnosis of encephalitis in patient with SARS-CoV-2.

An intravenous treatment with ceftriaxone $(50 \mathrm{mg} / \mathrm{kg} /$ day), vancomycin (15 mg/kg/day), acyclovir $(0.8 \mathrm{mg} / \mathrm{kg}$ every $8 \mathrm{~h}$ ), and steroids (dexamethasone $0.6 \mathrm{mg} / \mathrm{kg} /$ day) was immediately started. Lumbar puncture was performed and the cerebrospinal fluid (CSF) was clear and colorless. CSF laboratory tests showed WBC $0.5 \times 10^{7} / \mathrm{L}$ (normal value $<4$ ), protein $0.27 \mathrm{~g} / \mathrm{L}$ (normal 0.15-0.45), and normal glucose. The CSF specimen was negative for SARS-CoV-2 test. The patient did not evidence any bacterial or tuberculous infection of the CNS. Anti-HSV 1, varicella-zoster, Epstein-Barr, and CMV IgM antibodies were not detected in serum samples. After a cycle of high-dose intravenous methylprednisolone, a quick and complete remission of symptoms was observed. Two weeks later, the patient was discharged from hospital after two consecutive and negative throat swab tests for SARS-CoV-2. No consequences of the infection can be recorded at the present time.

\section{Discussion}

Paterson and colleagues [23] described in 2020 the emerging spectrum of COVID-19 neurological syndromes. GuillainBarré and Miller Fisher syndromes, acute necrotizing hemorrhagic encephalopathy, and acute disseminated encephalomyelitis have been described in COVID-19 patients suggesting a key role of the host-immune response mechanism rather than a direct neuro-invasion of the SARS-CoV-2 [24-27]. In fact, a subsidiary effect of the virus invasion is the reaction of the 


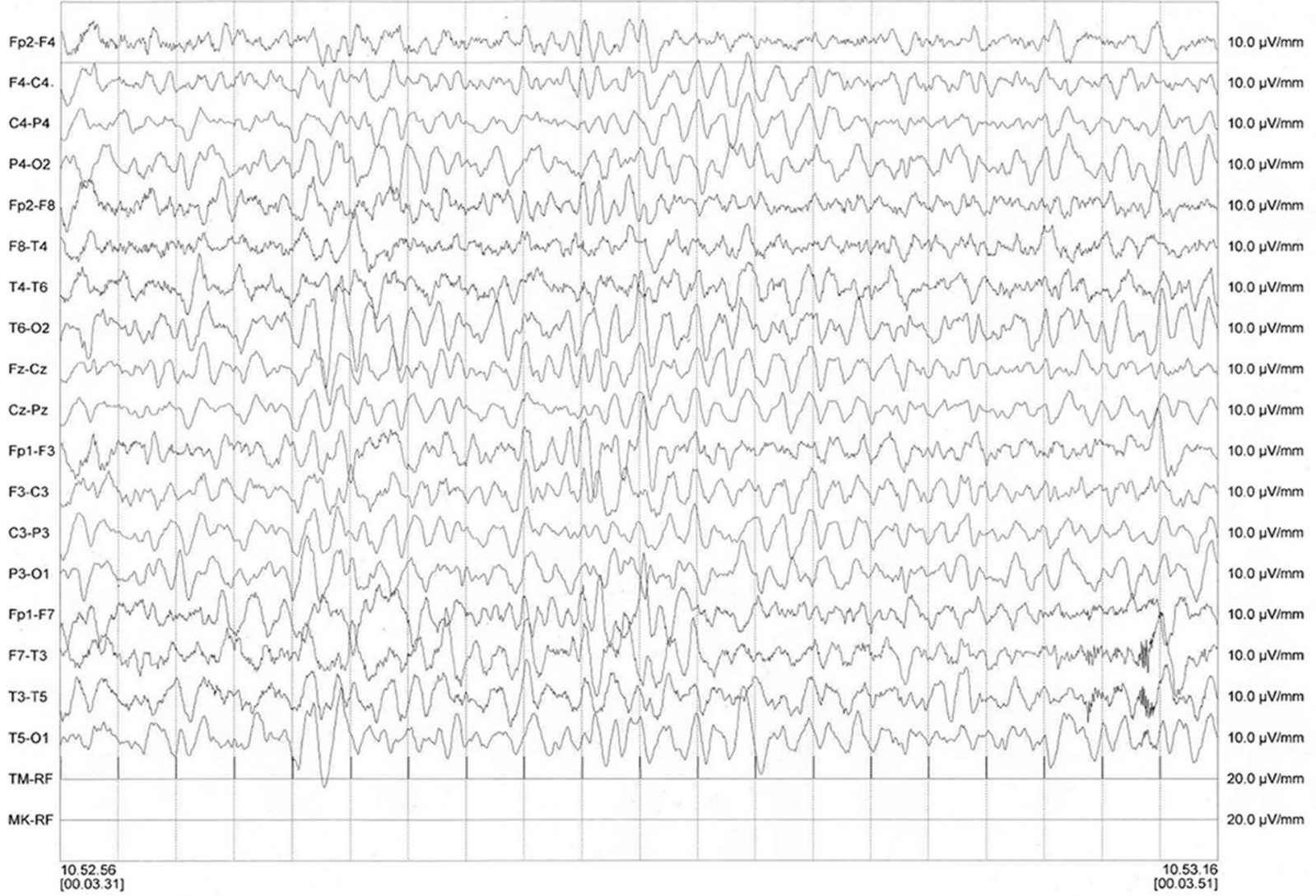

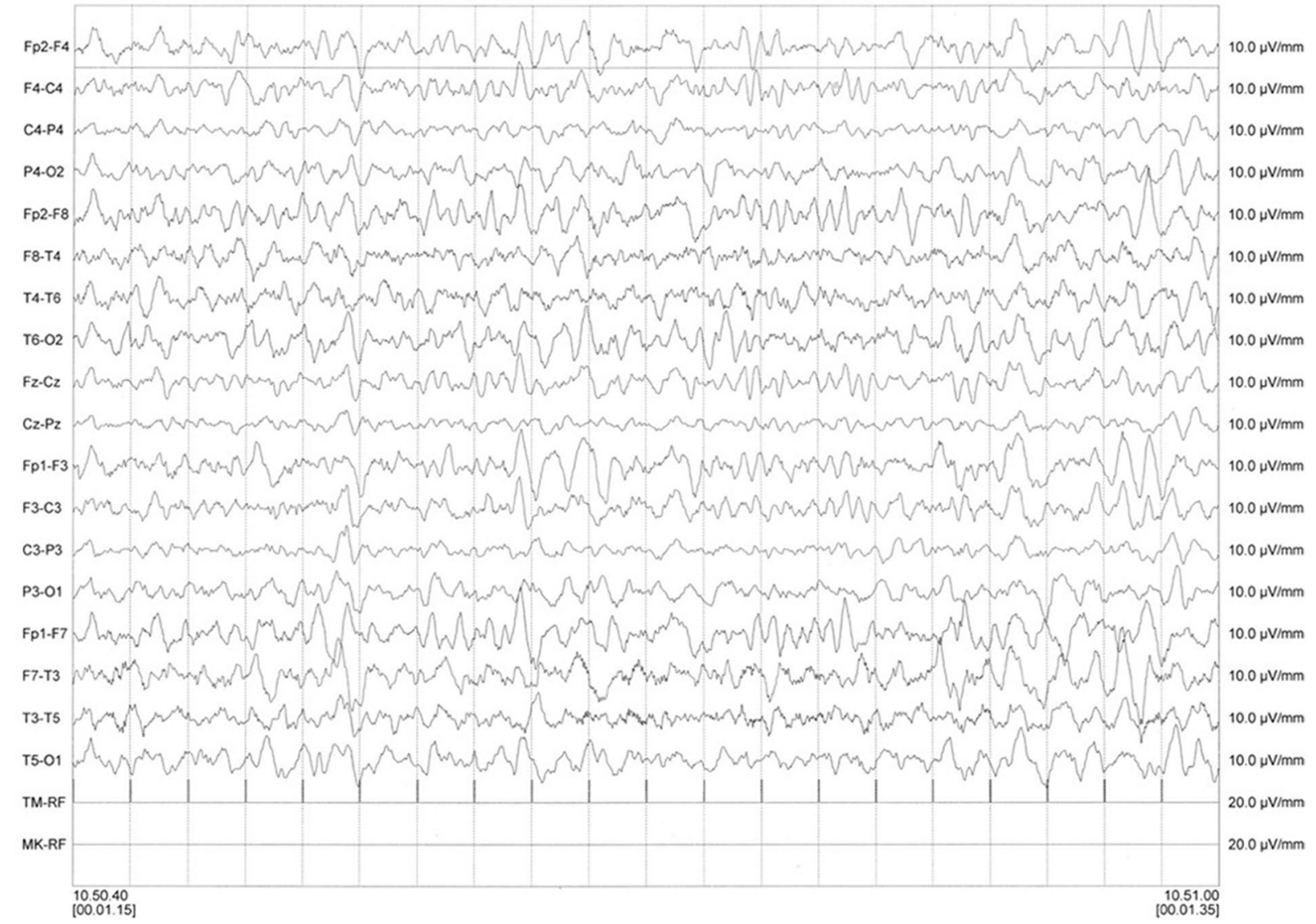


4Fig. 2 EEG showing a widespread slowing of the underlying rhythm

innate immune system leading to uncontrolled inflammatory response and the so-called cytokine storm. This, in turn, causes apoptosis of cells and vascular leakage and, in many cases, death [28].

The early suspicion of COVID-19 encephalitis and the appropriate CSF studies were the key to establish the correct diagnosis and timely management of the pathology. Despite the absence of CSF pleocytosis, the suspicion of CNS encephalitis should still be considered. Although the conclusive diagnosis of viral encephalitis largely depends on virus isolation, this can be difficult for COVID-19, because SARS-CoV-2 dissemination is transient and its CSF titer may be extremely low [29]. Consistently, anti-SARS-CoV-2 IgM and IgG were not detectable in the patient's CSF sample [29]. Therefore, as mentioned before, a physical evaluation of neurological symptoms and noninvasive tests such as brain RMN and EEG are important to lead a presumptive diagnosis [30]. From this case, it can be assumed that encephalitis in children is a complication of COVID-19 infection or, indeed, that it represents the first manifestation of the infection [29]. After multiplication in the primary (subcutaneous, respiratory mucosa, lymph nodes) and secondary (endothelium, muscle, marrow) sites, the SARS-CoV-2 would trigger an abnormal immune and/or inflammatory response, through still not completely understood mechanisms, causing damage to the vascular endothelium of the brain, arteriolar angiopathy, and in some cases direct, onconeural damage as described in literature in many dysimmune encephalitis [31]. The precise pathogenesis of encephalitis with SARS-CoV-2 infection is still unclear as well as its histopathological features. Viral epitopes resembling myelin antigens have the ability to activate myelin-reactive T-cell clones via molecular mimicry [32], and may thus elicit a CNS-specific autoimmune response, as in acute disseminated encephalomyelitis. Taken together, our findings support the hypothesis that corticosteroids therapy can be effective in the treatment of severe COVID-19-related encephalitis. Although rare, pediatric encephalitis cases related to SARS-CoV-2 para-infection and post-infection have already been reported in literature. Some results, highlighting symptom similarities and differences with the case here reported, are summarized in Table 1. Once more, it is important to highlight that the early establishment of the diagnosis and the immediate commencement of a management plan may contribute to a better outcome.

\section{Conclusions}

From this clinical case, it emerges that encephalitis in children can be a complication of COVID-19 infection, or it can be even considered that the encephalitis itself could be the initial manifestation of a not yet overt infection. Furthermore, the case suggests that neurological manifestations might be expected in COVID-19 infection, despite the absence of significant respiratory symptoms.

The neurological mechanism of viral agents, in general, and of COVID-19 in particular, could occur in different steps. Initially, we observe a multiplication in the primary (subcutaneous, respiratory mucous membranes, lymph nodes) and secondary (endothelium, muscle, marrow) sites. Then, the subsequent viremia would cause capillary infiltration, an abnormal immune and/or inflammatory response, which, with a still unknown mechanism, could damage the vascular endothelium of the brain, and cause an arteriolar angiopathy and development of lesions of the cerebral parenchyma of the relative affected regions. In conclusion, it appears quite evident that COVID-19 is a complex pathology made more complex by the presence of comorbidities, such as obesity and diabetes, and age of the patients. 
Fig. 3 Magnetic resonance imaging (MRI) of brain. Axial DWI images show an hyperintense focal lesion in the splenium of corpus callosum and an additional area in the left parietal subcortical site (A and B). Axial T2 image of the same lesion of splenium of corpus callosum that appears subtly hyperintense $(\mathbf{C})$. Axial MRI CE does not evidence any pathological enhancement of the lesion (D)
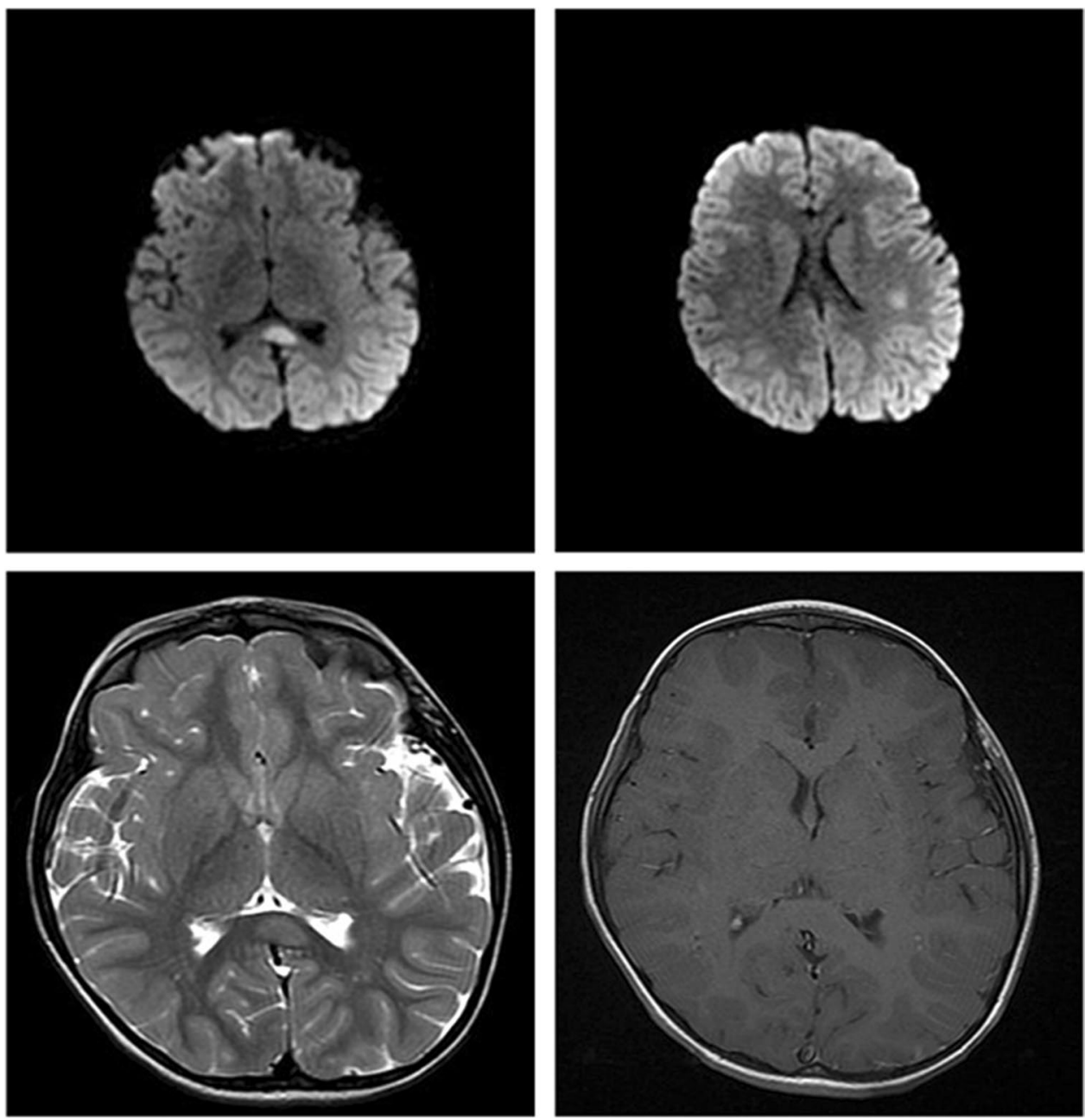

Table 1 Encephalitis pediatric cases developed as SARS-CoV-2 para-infection or post-infection in previously healthy patients. The sex of patients is indicated as $\mathrm{F}$ for female and $\mathrm{M}$ for male

\begin{tabular}{|c|c|c|c|c|}
\hline Reference & Age (years) & Condition & COVID-19 symptoms & Encephalitis symptoms \\
\hline Present case & $5 \mathrm{~F}$ & Para-infection & Cough, fever & $\begin{array}{l}\text { Neck swelling, right latero-cervical and painful lymphad- } \\
\text { enopathy, altered mental status, irritability, sleepiness, } \\
\text { lethargy, lack of energy }\end{array}$ \\
\hline [13] & $12 \mathrm{M}$ & Para-infection & Absent & $\begin{array}{l}\text { Severe emotional lability, facial tics, obsessive-compulsive } \\
\text { disorder }\end{array}$ \\
\hline [13] & $13 \mathrm{M}$ & Para-infection & Cough, fever, skin rush & $\begin{array}{l}\text { Obsessive-compulsive disorder, facial tic, hyperactivity, } \\
\text { aggressiveness, irritability, inattentiveness }\end{array}$ \\
\hline [33] & $16 \mathrm{~F}$ & Para-infection & Sore throat, fever & $\begin{array}{l}\text { Insomnia, anorexia, paranoia, hallucinations, severe encepha- } \\
\text { lopathy }\end{array}$ \\
\hline [34] & $10 \mathrm{~F}$ & Para-infection & $\begin{array}{l}\text { Ageusia, headache, malaise, } \\
\text { urinary incontinence }\end{array}$ & $\begin{array}{l}\text { Stop speaking, mobilizing, and using right arm, hypertonia, } \\
\text { brisk reflexes, right-sided Babinski, and sluggish pupils }\end{array}$ \\
\hline [35] & $13 \mathrm{~F}$ & Para-infection & Fever & $\begin{array}{l}\text { Headache, non-explosive vomiting, sudden-onset sensory } \\
\text { disorder }\end{array}$ \\
\hline [36] & $11 \mathrm{M}$ & Para-infection & Weakness & Epilepsy \\
\hline [37] & $7 \mathrm{M}$ & Para-infection & Absent & $\begin{array}{l}\text { Unsteady gait, ataxia, somnolence, seizures, not elicited deep } \\
\text { tendon reflexes }\end{array}$ \\
\hline [38] & $5 \mathrm{~F}$ & Para-infection & Fever, painful abdomen, diarrhea & $\begin{array}{l}\text { Neck swelling, right latero-cervical and painful lymphad- } \\
\text { enopathy }\end{array}$ \\
\hline [39] & 0.75 Unknown & Para-infection & Fever, breath shortness & Seizures, enlargement of lateral ventricles, hydrocephalus \\
\hline
\end{tabular}




\section{Declarations}

Ethical approval Ethical approval for this study was obtained from the Institutional Review Board Statement (May 19, 2021). All procedures performed were in accordance with the ethical standards of the institutional and national research committees and with the 1964 Helsinki Declaration and its later amendments or comparable ethical standards.

Informed consent The patient parents gave their written consent to analyze retrospectively her clinical data in order to publish the present case report.

Conflict of interest The authors declare no competing interests.

\section{References}

1. Kennedy PEG (2004) Viral encephalitis: causes, differential diagnosis, and management. J Neurol Neurosurg Psychiatry 75:110 i15. https://doi.org/10.1136/jnnp.2003.034280

2. Hu J, Jolkkonen J, Zhao C (2020) Neurotropism of SARS-CoV-2 and its neuropathological alterations: similarities with other coronaviruses. Neurosci Behav Rev 119:184-193. https://doi.org/10. 1016/j.neubiorev.2020.10.012

3. Li X, Geng M, Peng Y, Meng L, Lu S (2020) Molecular immune pathogenesis and diagnosis of COVID-19. J Pharm Anal 10:102108. https://doi.org/10.1016/j.jpha.2020.03.001

4. Kihira S, Delman BN, Belani P, Stein L, Aggarwal A, Rigney B, Schefflein J, Doshi AH, Pawha PS (2020) Imaging features of acute encephalopathy in patients with COVID-19: a case series. Am J Neuroradiol 41:1804-1808. https://doi.org/10.3174/ajnr. A6715

5. Huang Y, Yang C, Xu XF, Xu W, Liu SW (2020) Structural and functional properties of SARS-CoV-2 spike protein: potential antivirus drug development for COVID-19. Acta Pharmacol Sin 41:1141-1149. https://doi.org/10.1038/s41401-020-0485-4

6. Alenina N, Bader M (2019) ACE2 in brain physiology and pathophysiology: evidence from transgenic animal models. Neurochem Res 44:1323-1329. https://doi.org/10.1007/s11064-018-2679-4

7. Murgolo N, Therien AG, Howell B, Klein K et al (2021) SARSCoV-2 tropism, entry, replication, and propagation: considerations for drug discovery and development. PLoS Pathog 17:e1009225. https://doi.org/10.1371/journal.ppat.1009225

8. Hoffmann M, Kleine-Weber H, Schroeder S et al (2020) SARSCoV-2 entry depends on ACE2 and TMPRSS 2 and is blocked by a clinically proven protease inhibitor. Cell 181:271-280. https:// doi.org/10.1016/j.cell.2020.02.052

9. Wang D, Hu B, Hu C, Zhu F, Liu X, Zhang J, Wang B, Xiang H, Cheng Z, Xiong Y et al (2020) Clinical characteristics of 138 hospitalized patients with 2019 novel coronavirus-infected pneumonia in Wuhan, China. JAMA 323:1061-1069. https://doi.org/ 10.1001/jama.2020.1585

10. Nuzzo D, Cambula G, Bacile I, Rizzo M, Galia M, PMangiapane P, Picone P, Giacomazza D, Scalisi L (2021) Long-term brain disorders in PostCovid-19 neurological syndrome patient. Brain Sci 10:1947. https://doi.org/10.3390/brainsci11040454

11. Nuzzo D, Vasto S, Scalisi L, Cottone S, Cambula G, Rizzo M, Giacomazza D, Picone P (2021) Post-acute COVID-19 neurological syndrome: a new medical challenge. J Clin Med 11:454. https://doi.org/10.3390/jcm10091947

12. Leung NHL (2021) Trasmissibility and transmission of respiratory viruses. Nature Rev - Microbiol. https://doi.org/10.1038/ s41579-021-00535-6
13. Pavone P, Ceccarelli M, Marino S, Caruso D, Falsaperla R, Berretta M, Rullo EV, Nunnari G (2021) SARS-CoV-2 related paediatric acute-onset neuropsychiatric syndrome. Lancet Child Adolesc Health 5:e19-e21. https://doi.org/10.1016/S2352-4642(21) 00135-8

14. Zirpe KG, Dixit S, Kulkarni AP, Kakkar G, Gupta R, Bansal AR, Garg A et al (2020) Pathophysiological mechanisms and neurological manifestations in COVID-19. Indian J Crit Care Med 24:975-980. https://doi.org/10.5005/2Fjp-journals-10071-23592

15. Abdennour L, Zeghal C, Dème M, Puybasset L (2012) Interaction brain-lungs. Ann Fr Anesth Reanim 2012(31):e101-e107. https:// doi.org/10.1016/j.annfar.2012.04.013

16. Tang N, Li D, Wang X, Sun Z (2020) Abnormal coagulation parameters are associated with poor prognosis in patients with novel coronavirus pneumonia. J Thromb Haemost 18:844-847. https://doi.org/10.1111/jth.14768

17. Chowdhury MA, Hossain N, Kashem MA, Shaid A, Alam A (2020) Immune response in COVID-19. A review. J Inf Pub Health 13:1619-16-29. https://doi.org/10.1016/j.jiph.2020.07.001

18. Li Y, Fu L, Gonzales DM, Lavi E (2004) Coronavirus neurovirulence correlates with the ability of the virus to induce proinflammatory cytokine signals from astrocytes and microglia. J Virol 78:3398-3406. https://doi.org/10.1128/JVI.78.7.3398-3406.2004

19. Paramo JA (2020) Inflammatory response in relation to COVID19 and other prothrombotic phenotypes. Reumatologia Clinica (Eng. Ed.). https://doi.org/10.1016/j.reumae.2020.06.007

20. Camargo-Martinez W, Lozada-Martinez I, Escobar-Collazos A, Navarro-Coronado A, Moscote-Salazar L, Pacheco-Hernandez A, Janjua T, Bosque-Varela P (2021) Post-Covid 19 neurological syndrome: implications for sequelae's treatment. J Clin Neurosci 88:219-225. https://doi.org/10.1016/j.jocn.2021.04.001

21. Frontera JA, Yang D, Lewis A, Patel P, Medicherla C et al (2021) A prospective study of long-term outcomes among hospitalized COVID-19 patients with and without neurological complications. J Neurol Sci 426:17486. https://doi.org/10. 1016/j.jns.2021.117486

22. Gonzalez-Herazo MA, Silva-Nugnoz DC, Guevara-Martinez PA, Lozada-Martinez ID (2021) Post-COVID 19 neurological syndrome: a fresh challenge in neurological management. Polish $\mathrm{J}$ Neurol Neurosurg. https://doi.org/10.5603/PJNNS.a2021.0052

23. Paterson RW, Brown RL, Benjamin L, Nortley R, Wiethoff S, Bharucha $\mathrm{T}$ et al (2020) The emerging spectrum of COVID-19 neurology: clinical, radiological and laboratory findings. Brain 143:3104-3120. https://doi.org/10.1093/brain/awaa240

24. Gutierrez-Ortiz C, Mendez A, Rodrigo-Rey S, San Pedro-Murillo E, Bermejo-Guerrero L, Gordo-Manas R, de Aragon-Gomez F, Benito-Leon J (2020) Miller Fisher syndrome and polyneuritis cranialis in COVID-19. Neurology 95:e601-e605. https://doi.org/ 10.1212/WNL.0000000000009619

25. Novi G, Rossi T, Pedemonte E, Saitta L, Rolla C, Roccatagliata L, Inglese M, Farinini D (2020) Acute disseminated encephalomyelitis after SARS-CoV-2 infection. Neurol Neuroimmunol Neuroinflamm 7:e797. https://doi.org/10.1212/NXI.0000000000 000797

26. Toscano G, Palmerini F, Ravaglia S, Ruiz L, Invernizzi P, Cuzzoni MG, Franciotta D, Baldanti F, Daturi R, Postorino P, Cavallini A, Micieli G (2020) Guillain-Barré syndrome associated with SARSCoV-2. N Engl J Med 382:2574-2576. https://doi.org/10.1056/ nejmc2009191

27. Weyhern CV, Kaufmann I, Neff F, Kremer M (2020) Early evidence of pronounced brain involvement in fatal COVID-19 outcomes. Lancet 395:e109. https://doi.org/10.1016/S0140-6736(20) 31282-4

28. Tang Y, Liu L, Zhang D, Xu Z, Ji J, Wen C (2020) Cytokine storm in COVID-19: the current evidence and treatment strategies. Front Immunol 11:1708. https://doi.org/10.3389/fimmu.2020.01708 
29. Haider H, Siddiqa A, Ali N, Dhallu M (2020) COVID-19 and the brain: acute encephalitis as a clinical manifestation. Cureus 12:e10784. https://doi.org/10.7759/2Fcureus. 10784

30. Nuzzo D, Picone P (2020) Potential neurological effects of severe COVID-19 infection. Neurosci Res 158:1-5. https://doi.org/10. 1016/j.neures.2020.06.009

31. Le Dault E, Lagarde S, Guedj E, Dufournet B, Rey C, Kaphan E, Tanguy G, Bregigeon M, Sagui E, Brosset C (2016) Unexplicated neuropsychiatric disorders: do not ignore dysimmune encephalitis. A case report of a dysimmune encephalitis with anti-leucine rich glioma inactivated 1 (LGI-1) antibodies. Rev Med Interne 37:127-130. https://doi.org/10.1016/j.revmed.2015.06.007

32. Wucherpfennig KW, Strominger JL (1995) Molecular mimicry in T cell-mediated autoimmunity: viral peptides activate human $\mathrm{T}$ cell clones specific for myelin basic protein. Cell 80:695-705. https://doi.org/10.1016/0092-8674(95)90348-8

33. Gaughan M (2021) Pediatric parainfectious encephalitis associated with COVID-19. Neurology 96:541-544. https://doi.org/10. 1212/WNL.0000000000011476

34. Vraka K, Ram D, West S, Chia WYE, Kurup P, Subramanian G, Tan HJ (2021) Two paediatric patients with encephalopathy and concurrent COVID-19 infection: Two sides of the same coin? Case Rep Neurol Med:6658000. https://doi.org/10.1155/2021/ 6658000

35. Conto-Palomino NM, Cabrera-Bueno ML, Vargas-Ponce KG, Rondón-Abuhadba EA, Atamari-Anahui N (2020) Encephalitis associated with COVID-19 in a 13-year-old girl: a case report. Medwave 20:e7985. https://doi.org/10.5867/medwave.2020.07. 7984
36. McAbee GN, Brosgol Y, Pavlakis S, Agha R, Gaffoor M (2020) Encephalitis associated with COVID-19 infection in an 11-yearold child. Pediatr Neurol 109:94. https://doi.org/10.1016/j.pedia trneurol.2020.04.013

37. Sarigecili E, Arslan I, Ucar HK, Celik U (2021) Pediatric antiNMDA receptor encephalitis associated with COVID-19. Child's Nerv Syst 14:1-4. https://doi.org/10.1007/s00381-021-05155-2

38. Siracusa L, Cascio A, Giordano S, Medaglia AA, Restivo GA, Pirrone I, Saia GF, Collura F, Colomba C (2021) Neurological complications in pediatric patients with SARS-CoV-2 infection: a systematic review of the literature. Ital J Pediatr 47:123. https:// doi.org/10.1186/s13052-021-01066-9

39. Sofijanova A, Bojadzieva S, Duma F, Superlishka E, Murtezani A, Jordanova O (2020) Severe encephalitis in infant with COVID19: a case report. Maced J Med Sci 8:514-517. https://doi.org/10. 3889/oamjms.2020.5485

40. Hess DC, Eldahshan W, Rutkowski E (2020) COVID-19-related stroke. Transl Stroke Res 11:322-325. https://doi.org/10.1007/ s12975-020-00818-9

Publisher's note Springer Nature remains neutral with regard to jurisdictional claims in published maps and institutional affiliations. 